\title{
Experimental test stand for development of an opposed-piston engine and initial results
}

The article presents the reason for developing a OD predictive and diagnostic model for opposed-piston (OP) engines. Firstly, a description of OP engines, together with their most important advantages and challenges are given together with current research work. Secondly, a PAMAR-4 engine characteristic is presented. After that the proposed OD predictive model is described and compared with the commercially availible software. Test stand with most important sensors and solutions are presented. After that the custom Engine Control Unit software is characterized together with a OD diagnostic model. Next part discusses specific challenges that still have to be solved. After that the preliminary test bed results are presented and compared to the OD simulations. Finally, the summary together with possible future improvement of both OD predictive model and test bed capabilities are given.

Key words: opposed-piston, combustion, heat release, 2-stroke

\section{Introduction}

Opposed-piston engines allows achieving high thermodynamic efficiency inter alia due to lack of a cylinder head and better shape of the combustion chamber [1,2]. During PAMAR-4 project it turned out that there are no readymade tools which can be used for analyzing the 2-stroke opposed-piston engine operation, neither in design phase nor during measurements on the test bed. A set of supportive numerical tools has been developed, concerning mainly modelling 3D scavenging and heat transfer calculations using CFD. Unfortunately, those tools are very computationally expensive and not particularly useful for transient operation simulations or as a part of prediction control system which could be used for a HCCI control. It has been assumed that a simple 0D predictive and diagnostic custom tailored model will address the needs of improving the efficiency of the future opposed-piston engines and allow implementing closed-loop control basing on cylinder pressure signal.

\section{Opposed-piston engines}

\subsection{Geometry}

An opposed-piston engine is a subtype of internal combustion engine with no cylinder head. Two pistons are reciprocating opposite to each other, both working in one cylinder (Fig. 1). They can work as 4-stroke, but most of them are 2-stroke engines and scavenging is usually controlled by piston-ported valves. Combustion chamber is formed between moving pistons.

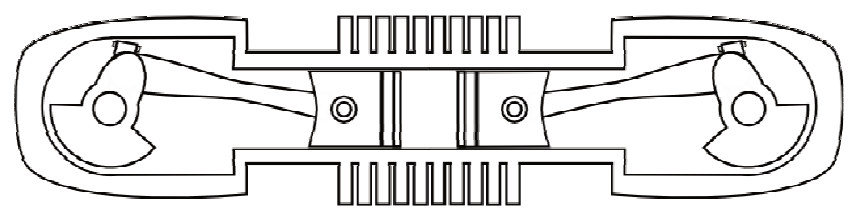

Fig. 1. Opposed-piston engine

First opposed-piston engines emerged in the late XIX century [1], while the most famous of them were used during the WWII (Jumo series by Junkers company). In the
1946 Sulzer 8G18 Series achieved 39.5\% brake thermal efficiency.

\subsection{Advantages of $O P$ engines}

Shape of a combustion chamber: Heat generated is proportional to the volume (V) of a combustion chamber, while heat loses are proportional to the surface area (SA). The SA/V factor is nearly twice lower in OP engines than in conventional, leading to higher thermal efficiency $[1,2]$.

Lack of a cylinder head: Cylinder head heat loses are significant due to necessity of cooling poppet valves. Eliminating cylinder head simply eliminates these loses, which improves thermodynamic efficiency. Moreover, it leads to reducing the emission of unburned hydrocarbons and carbon monoxide, mainly formed at the cold walls of the head, where flame is being quenched.

Possible high stroke/bore ratio: Engines with higher S/B have smaller surface area exposed to combustion gases which improves thermal efficiency. Also mechanical efficiency is affected: while increasing S/B factor the bearing friction decreases proportionally to the lower forces (lower piston area, same pressure). In OP engines the stroke is split between two pistons, which gives high S/B without increasing mean piston speed (lower the speed - better the efficiency) [12].

\subsection{Challenges connected with the $O P$ engines}

High thermal load: 2-stroke engines have no additional two strokes to exchange the charge (during which the engine is cooled). Also, high power concentration leads to problems with exhaust ports durability (usually they have to be water cooled) and piston head wear.

Changing linear to rotary motion: Classical engines inherently have one shaft. The challenge with the OP is to take the power from 2 pistons and transfer it in effective way to one shaft. There are single, double or multishift solutions [1], rotary or barrel engines [6] but it is hard to achieve comparable or better mechanical efficiency than in crankshaft mechanism without in-depth analysis.

Side injection: In the OP engines injection is being made perpendicularly to the piston motion while in stand- 
ard engines injection is parallel and central. Classical injectors have problem with even fuel distribution in a combustion chamber of the OP engines which can lead to an inefficient combustion. Moreover, there is a risk of cylinder liner or piston rings fuel impingement - that makes charge nonuniform and generates local high thermal loads. Fuel impingement can also destroy lubrication film, leading to increased emission, oil consumption and faster pistoncylinder wear.

\subsection{Current research work in the world}

Kharkiv Morozov Machine Building Design Bureau designed and introduced a 2-stroke, 6-cylinder, liquidcooled multi-fuel diesel engine 6TD-2 with horizontal placement of cylinders and opposed pistons with $882 \mathrm{~kW}$, being able to use diesel, jet engine fuel, petrol or any mixtures of them. This engine is used in T-84 main battle tank since 1990.

Achates Power is an American company founded in 2004, developing a 2-stroke, 3 cylinder, OP compression ignition engine (4,9 L, $205 \mathrm{~kW}$ power). In 2016 they surpassed 7,000 hours of dynamometer testing. They best brake thermal efficiency point is at the moment is $44 \%$ (191 $\mathrm{g} / \mathrm{kWh}$ ) and they are predicting a possibility to achieve 180 $\mathrm{g} / \mathrm{kWh}$ in production level engine [3] while meeting exhaust emissions US2010 EPA requirements using conventional after-treatment system.

EcoMotors is an American company founded in 2008 developing and commercializing an opposed-piston opposedcylinder (OPOC) engine. In 2011 they struck a partnership with Generac (large manufacturer of backup power generators) and they are developing together a $240 \mathrm{~kW}$ power pack. They created their second R\&D center in China (main target market) to adapt technology and engine to local reality.

Pinnacle Engines is a start-up with an idea of commercializing a 4-stroke, SI, opposed-piston engine. It uses "Cleeves" cycle [4], changing constant volume combustion to constant pressure combustion depending on operating condition. The production of $110 \mathrm{~cm}^{3}$ scooter engines will be started in 2017 in Asia [5].

\subsection{Applications}

In authors opinion there are three main reasonable applications for OP engines utilizing adequate advantages:

- distributed power generation (high fuel efficiency, good power-to-weight and power-to-bulk ratio),

- military (multifuel potential and high power-to-bulk ratio),

- automotive, as a range extender for hybrids (high fuel efficiency and good power-to-weight ratio).

The 2-stroke OP engine could be a worse solution than normal 4-stroke for direct propulsion of a car as scavenging process can be only optimized properly for a given load and rotation speed.

\section{Object of study - PAMAR type engine}

A PAMAR-4 engine is a 2-cylinder, opposed-piston, 2stroke barrel engine (Fig. 2, 3). It has been designed under the Polish-Norwegian Cooperation Research conducted by the National Research and Development Centre, project: Investigations of HCCI in an innovative barrel engine.

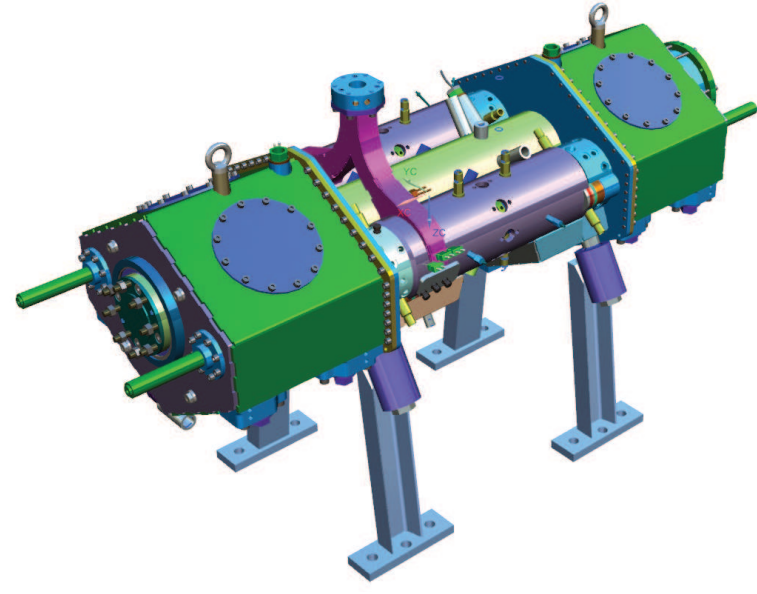

Fig. 2. PAMAR-4 CAD model without auxiliary equipment

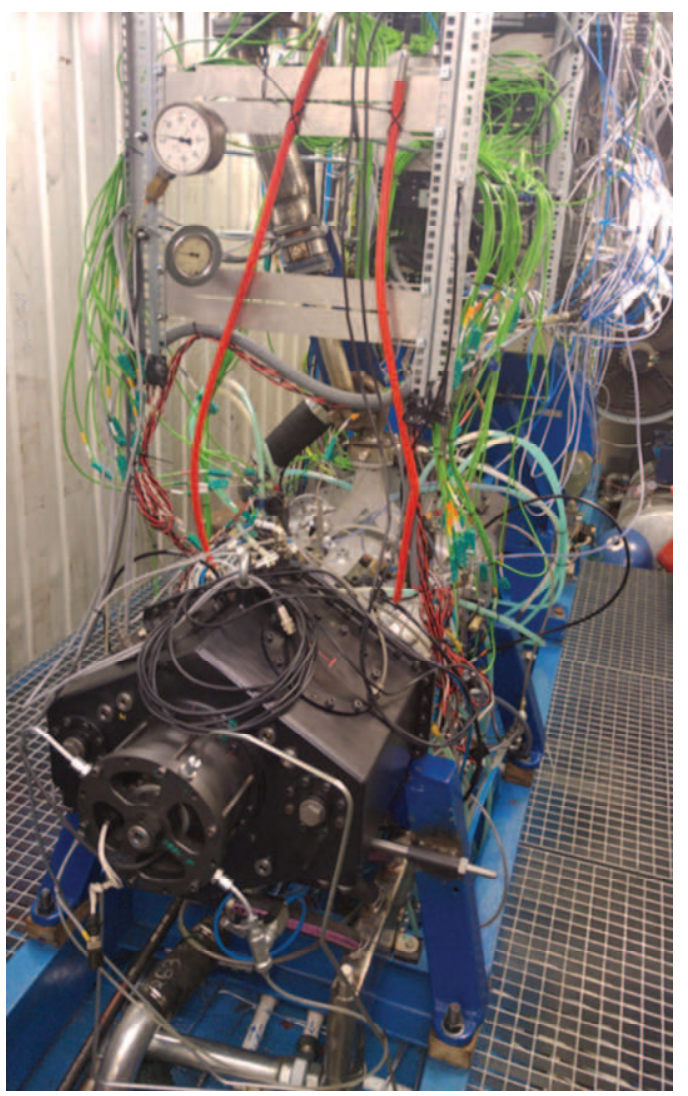

Fig. 3. PAMAR-4 on the test bed

Main properties:

- HCCI combustion on gasoline under various loads,

- 100 kW@1500 rpm, 1700 dm³,640 Nm@1500 rpm,

- multifuel potential (both liquid and gaseous),

- variable compression ratio,

- variable valve timing,

- variable phase shift.

PAMAR-4 is using a wobble plate mechanism. Shaft is not straight but bended with a proper angle - this makes plate rotate in other axis than shaft. The plate has a special pin (crosshead) which moves on the crosshead guide. This slider is blocking the plate's rotation and makes the shaft rotate while the plate pin is only having a pendulum like motion (wobbling) (Fig. 4). 


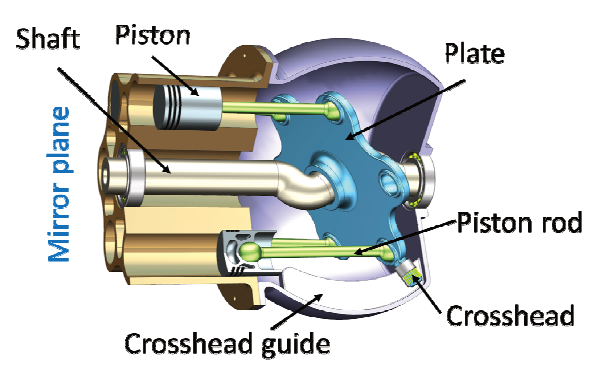

Fig. 4. PAMAR-4 wobble plate (blocked by crosshead, half of the engine)

The combustion chamber has mounted:

- piezoelectric gasoline direct injector (VDO Siemens 1353 7565137-03 - also used for direct water injection),

- piezoelectric diesel direct injector (Delphi A6510701287),

- piezoelectric pressure transducer (Kistler 6055C80),

- spark plug (NGK ER9EHIX),

- glow plug (NGK D-Power CZ303).

\section{Heat release in $0 \mathrm{D}$ model}

\subsection{Introduction}

The main reason for developing a OD model is a need to have a simple prediction algorithm for controlling a $\mathrm{HCCI}$ combustion on gasoline under various loads from cycle to cycle. The solver is based on a Single Zone Model, which is a common approach in modelling SI in commercial software [11]. The system is balanced using the first law of thermodynamics for a stationary open system:

$$
\mathrm{dU}=\delta \mathrm{Q}-\delta \mathrm{W}+\mathrm{h}_{\mathrm{j}} \mathrm{dm}_{\mathrm{j}}
$$

where: dU - change in the total internal energy of incylinder charge, $\delta \mathrm{Q}-$ total heat transfer across the cylinder boundary, $\delta \mathrm{W}=\mathrm{pdV}$ - work transfer rate out of the system, $\mathrm{h}_{\mathrm{j}}$ - specific enthalpy of gas mixture flowing through the boundary $\mathrm{j}$ (intlet, outlet, blowby, injection etc.).

On the other hand the $\mathrm{dU}$ term can be expressed as:

$$
\mathrm{dU}=\mathrm{m}_{\mathrm{i}} \mathrm{c}_{\mathrm{vi}} \mathrm{dT}+\mathrm{u}_{\mathrm{i}} \mathrm{m}_{\mathrm{i}}
$$

where: $\mathrm{i}$ - specie index. Mass conversion is assumed by Wiebe function.

Mass flow through ports is approximated by equation for compressible flow through an orifice derived from a one-dimensional isentropic flow. Non-isentropic effects are modelled by discharge coefficient $\mathrm{C}_{\mathrm{d}}$. Coefficient of discharge is usually in range from 0.75 to 0.85 [8] and is also parametrized as a function of port open fraction.

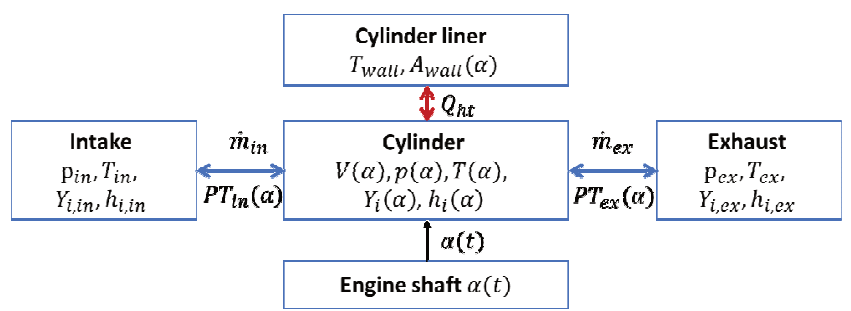

Fig. 5. Diagram of developed simple thermodynamic 0D model
Table 1. Description of the Fig.5

\begin{tabular}{|l|c|l|}
\hline Value & Unit & \multicolumn{1}{|c|}{ Meaning } \\
\hline $\mathrm{V}(\alpha)$ & $\mathrm{m}^{3}$ & Volume of cylinder \\
\hline $\mathrm{p}(\alpha)$ & $\mathrm{Pa}$ & Mass-averaged in-cylinder pressure \\
\hline $\mathrm{T}(\alpha)$ & $\mathrm{K}$ & Mass-averaged in-cylinder temperature \\
\hline $\mathrm{Y}_{\mathrm{i}}(\alpha)$ & - & Species mass fractions \\
\hline $\mathrm{h}_{\mathrm{i}}(\alpha)$ & $\mathrm{J} / \mathrm{kg}$ & Enthalpy \\
\hline $\mathrm{PT}_{\text {in }}(\alpha), \mathrm{PT}_{\text {ex }}(\alpha)$ & $\mathrm{m}^{2} \alpha$ & Port timing \\
\hline $\mathrm{m}_{\text {in }}(\alpha), \mathrm{m}_{\mathrm{ex}}(\alpha)$ & $\mathrm{kg} / \mathrm{s}$ & Mass flow through ports \\
\hline $\mathrm{T}_{\text {wall }}, \mathrm{A}_{\text {wall }}(\alpha)$ & $\mathrm{K}, \mathrm{m}^{2}$ & $\begin{array}{l}\text { Reference area and temperature for } \\
\text { Woschni correlation }\end{array}$ \\
\hline
\end{tabular}

\subsection{Geometry}

In 2-stroke, opposed-piston engine the volume and valve timing is directly connected with the port geometry. A computer program has been prepared to calculate effective compression ratio, effective stroke volume, valve timing, combustion chamber surface area etc. for a given port geometry. Additionally, the variable systems are taken into consideration - they are implemented as the change of piston motion function. The program return volume function and timing. The piston displacement in PAMAR-4 engine can be described by (3) and (4). F is a function of wobble plate mechanism, VCR is a shift from variable compression ratio system and VVT is a shift from variable valve timing (in this came a variable piston timing). Exhaust piston leads intake piston by phase $\phi$ to allow charge exchange.

$$
\begin{gathered}
\mathrm{X}_{\mathrm{in}}(\alpha)=\mathrm{F}(\alpha-\phi / 2)+\mathrm{VCR}+\mathrm{VVT} \\
\mathrm{X}_{\mathrm{ex}}(\alpha)=\mathrm{F}(\alpha+\phi / 2)+\mathrm{VVT}
\end{gathered}
$$

\subsection{Thermodynamic data}

NASA 7-coefficient polynomial parametrization is used to compute the species reference-state thermodynamic properties: heat capacity at constant pressure $\mathrm{J} / \mathrm{kmolK}$, specific standard molar enthalpy of formation $\mathrm{kJ} / \mathrm{mol}$ and specific standard molar entropy: J/kmolK [7]. Assuming ideal gas model for working medium (standard assumption basing on [8]) all needed thermodynamic properties like heat capacity at constant pressure, volume, heat capacity ratio are calculated with a help of Cantera.

\subsection{Heat transfer}

As only cylinder volume is taken into consideration the conduction is not modeled. Radiation is omitted (the engine is working on gasoline, there is no radiating soot like in diesel-fueled compression ignition engines). The convection is modeled by Newton's law (5) with instantaneous special average coefficient for convective heat-transfer calculated using Woschni formula $(6)[9,10]$ :

$$
\begin{gathered}
\mathrm{Q}=\mathrm{h}_{\mathrm{k}}\left(\mathrm{T}_{\mathrm{g}}-\mathrm{T}_{\mathrm{w}}\right) \\
\mathrm{h}_{\mathrm{k}}=110 \mathrm{~B}^{-0.2} \mathrm{p}^{0.8} \mathrm{v}^{0.8} \mathrm{~T}^{-0.55}
\end{gathered}
$$

where: B - cylinder bore [m], $\mathrm{p}$ - in-cylinder pressure [bar], $\mathrm{v}$ - characteristic velocity connected with (7) mean piston speed $S_{p}$, constants $C_{1}$ and $C_{2}$ depending on cycle's period and difference between current $(\mathrm{p})$ and motoring pressure $\left(\mathrm{p}_{\mathrm{m}}\right)[\mathrm{m} / \mathrm{s}], \mathrm{C}_{\text {ref }}$ is calculated from known reference state and displaced volume, $\mathrm{T}_{\mathrm{g}}$ - in-cylinder gas temperature $[\mathrm{K}]$. 


$$
\mathrm{v}=\left(\mathrm{C}_{1} \mathrm{~S}_{\mathrm{p}}+\mathrm{C}_{\mathrm{ret}} \mathrm{C}_{2}\left(\mathrm{p}-\mathrm{p}_{\mathrm{m}}\right)\right)
$$

In the $0 \mathrm{D}$ model there are four distinguished areas (Fig. 6):

- intake piston area and its reference temperature,

- exhaust piston area and its reference temperature (exhaust piston is hotter as intake piston is cooled by fresh charge),

- combustion chamber area and its reference temperature,

- cylinder liner area vs angle and its reference temperature.

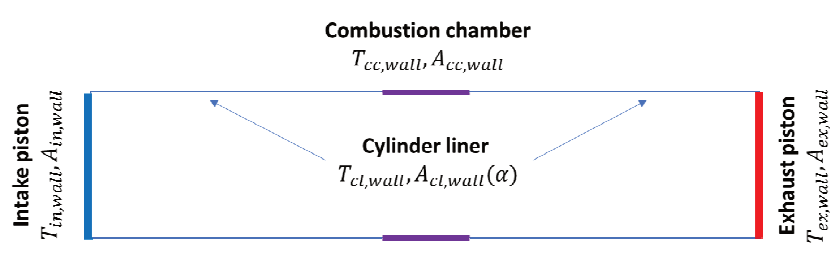

Fig. 6. Boundary conditions for heat-transfer calculations

\subsection{Heat release}

Heat release is modelled by $\mathrm{S}$-shaped mass fraction burned profile described by Wiebe function. Wiebe function (8) is widely used in engine software packages [11], e.g. GT Power uses single Wiebe function for SI engine and multi-Wiebe function for CI engine modelling. AVL Boost uses single Wiebe function for combustion process and two-zone Wiebe for NOx calculations. Ricardo Wave has a SI Wiebe combustion model and CI Wiebe based semipredictive model with pilot injection.

$$
\mathrm{x}_{\mathrm{b}}=1-\exp \left(-\mathrm{a}\left(\left(\theta-\theta_{0}\right) / \Delta \theta\right)^{\mathrm{m}+1}\right)
$$

where: $\mathrm{x}_{\mathrm{b}}$ - mass fraction burned, $\theta$ - current crank angle, $\theta_{0}$ - start of the combustion (ignition in SI, approximately injection in $\mathrm{CI}$ ), $\Delta \theta$ - combustion duration, a, $\mathrm{m}$ - adjustable parameters.

\subsection{Calculation solver}

Calculation algorithm:

1. If ports are open calculate mass change through the boundaries (intake/exhaust).

2. Recalculate gas composition $Y_{i}$ change due to mass flow through the boundaries (using scavenging model).

3. Calculate new gas composition $\mathrm{Y}_{\mathrm{i}}$ according to Wiebe function.

4. Update gas properties (new composition).

5. Get current volume $\mathrm{V}$ and calculate $\mathrm{dV}$.

6. Calculate components of the equation (1): work, change in internal energy due to combustion, mass flow through the boundaries and change in internal energy due to heat transfer through the boundaries using Woschni correlations.

7. Calculate dT and new temperature from equation (2).

8. Calculate pressure from ideal gas law.

8. Proceed to the next time step (time step is 0.1 CAD)

\section{Test stand}

PAMAR-4 engine together with whole dyno is encapsulated in a 40 feet High Cube Pallet Wide marine-type container enabling transport.

\subsection{Engine indication}

Engine crank position is measured by two Heidenhein ERN 1303600 HTL quad incremental encoders connected to NI 9411 module. PXI-7853R FPGA couples encoder signal with pressure acquisition to precisely gather pressure vs crank angle characteristic with $0.1 \mathrm{CAD}$ resolution.

In cylinder pressure is measured by piezoelectric Kistler $6055 \mathrm{C} 80$ pressure transducer with diaphragm that allows measurements during engine knocking. Piezoelectric sensors outputs charge, in case of $6055 \mathrm{C} 80$ it is $-20 \mathrm{pC} / \mathrm{bar}$ (output range is from 0 to $5000 \mathrm{pC}$ as measuring range is 0 250 bar). Dewetron Charge B charge module is used to read the charge and convert it to voltage signal $(-5 \mathrm{~V}$ to $5 \mathrm{~V})$ which can be further analyzed. It has built-in Bessel or Butterworth (software programmable) filter and grounds each engine cycle to help keep data from drifting out of digitiser range. Charge modules are stored in Dewe- 800 mainframe (special model prepared for DAQP isolated analog input amplifier modules).

Pressure signal is acquired by both Dewetron and National Instruments system. Dewetron uses DEWE-ORION1616-500 A/D card (with 16 simultaneous sampled singleended channels at $500 \mathrm{kSamples} / \mathrm{s}$ each), controlled by DeweSoft which is used for simple in-cylinder pressure and heat release analysis. National Instruments system uses NI PXI-7853R LX85 Multifunction RIO (8 analog inputs, 750 $\mathrm{kHz}, 16-b i t)$ under control of LabView-written custom data acquisition software, tailored for opposed-piston engines.

\subsection{Torque measurement and power absorption}

Torque is measured by load cell of Froude Hofmann's AG400 eddy current dynamometer with a capacity of 400 $\mathrm{kW}$ and $2000 \mathrm{Nm}$ (inertia is $1.107 \mathrm{~kg} \mathrm{~m}^{2}$ ). Load cell is connected to Texcel V4 Controller, measurement accuracy is $0.25 \%$. The speed is measured by a Hall-effect sensor counting slopes on a toothed wheel mounted on the shaft half coupling hub (accuracy is $\pm 1 \mathrm{rpm}$ ). Engine is coupled to the dynamometer with an Elbe 100 Cardan shaft of 8,200 $\mathrm{Nm}$ capacity which has been dynamically balanced.

\subsection{Fuel system}

Injection system is patent pending solution (P-419918, "Device for providing and very precise measuring of small amounts of liquids under high pressure") which allows precise measurement of very low flows (even less than 0.001 LPM) under very high pressure (up to 300 bar). The double acting piston pumps the gasoline out of the hydraulic cylinder under pressure generated by the hydraulic oil. The piston position is measured using TK LA46K magnetostrictive linear encoder thus volumetric flow is known (Fig. 7). Injectors are controlled by NI 9751 Direct Injector

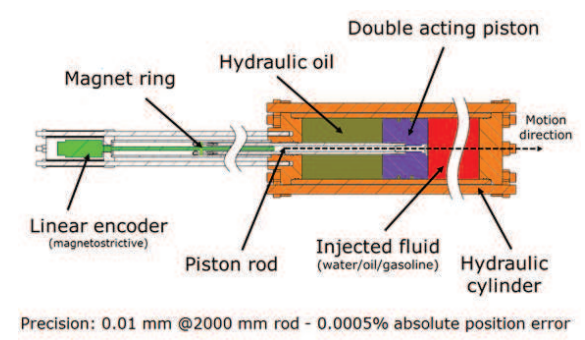

Fig. 7. PAMAR-4 fuel consumption measurement module

Driver Module, ignition is set by NI 9403 TTL Digital Input/Output Module. 


\subsection{Air charging}

Air intake system is 2-stage boosted. 1-st stage is Garrett GT1749V variable nozzle turbocharger, 2-nd stage is Eaton TVS R410 5th generation mechanical supercharger powered by an electrical inverter-controlled engine. Air is water intercooled to improve charging efficiency. Pressure is regulated by bypasses controlled by throttles.

Air mass flow is measured using Bosch air-mass meter (0 281002802 - a typical automotive measurement, about $3 \%$ error) and Rosemount Annubar 3051SFA (industrial grade flow meter, less than $1 \%$ error). Temperatures are measured using K-type $1.5 \mathrm{~mm}$ thermocouples connected to NI PXIe-4353 32-Ch Thermocouple Input (accuracy 0.3 $\left.{ }^{\circ} \mathrm{C}\right)$. Pressure is measured using NXP MPX4250AP $(1.5 \%$ accuracy) or NXP MPX5500DP (2.5\% accuracy) accordingly to the pressure range.

\subsection{Exhaust system}

The pressure in exhaust is measured using a fast, water cooled Kulite EWCTV-312M-25bar A pressure transducer (range $0-25$ bar, accuracy $\pm 0.1 \%$ FSO BFSL). The emissions are measured using Bosch BEA 460: CO $(0.001 \%$ vol resolution), $\mathrm{HC}$ (1 ppm resolution), $\mathrm{CO} 2(0.01 \%$ vol resolution), $\mathrm{NO} / \mathrm{NO}_{2}$ (1 ppm resolution), and $\mathrm{O}_{2}(0.01 \%$ vol resolution). There is no catalyzer at the moment.

\section{Data acquisition system}

Dewesoft, supplied with Dewetron charge amplifiers, has capabilities of measuring in-cylinder data, calculating simple heat generation and knock detection. Unfortunately, it's neither possible to control the engine with it nor to make more sophisticated thermodynamic calculations. This forced authors to develop a custom Engine Control Unit in LabView, which will allow both data acquisition and closed-loop control.

\subsection{Data acquisition system configuration}

Data acquisition hardware is based on National Instruments PXI platform with auxiliary units (Fig. 8). System has:

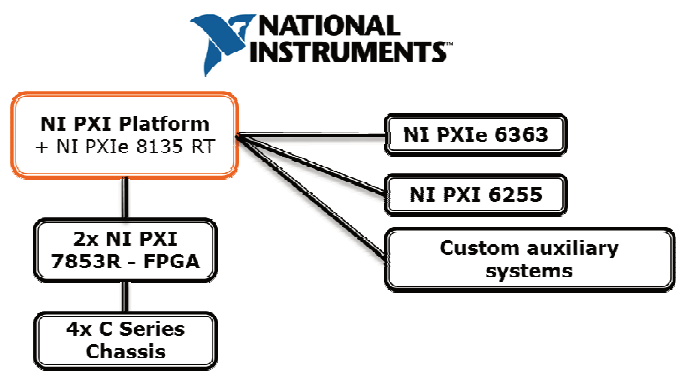

Fig. 8. Block diagram of data acquisition system

- 96 thermocouple inputs, 64 of them used for measuring the temperature of the engine parts (Fig. 9),

- 16 fast analog inputs with independent sampling rate up to $750 \mathrm{kHz}, 16$-bit,

- 112 analog inputs,

- 22 analog outputs,

- 104 digital in/out channels,

- digital interfaces (CAN Bus, RS-485, TCP/IP, UDP),
- C Series drivers for direct and port injectors, spark plugs, throttles and encoders.

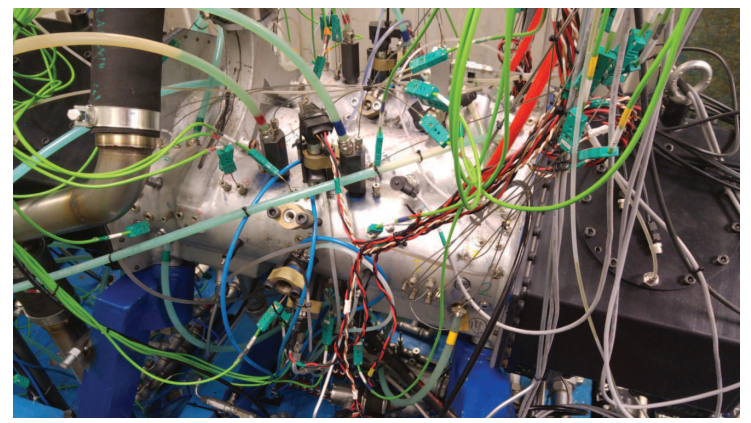

Fig. 9. 64 thermocouples embedded in PAMAR-4 engines

\subsection{Software overview}

Application is split between PC, PXI and 2xFPGA (Fig. 10). A communication between PC and PXI is solved by using Network Streams over the Ethernet. PXI and FPGA communicates using Direct Memory Access or Front Panel Communication depending on data. Application consists of 4 main modules:

- PX - user module, which allows results visualization and control,

- PXI - real time computer which makes the data acquisition and automatic control by using feedback loops,

- FPGA1/FPGA2 - FPGA matrixes used for fast channel data acquisition (in-cylinder pressure, Kulite pressure transducers, vibrations, knock sensor, encoder) and controlling C Series drivers (ignition, injection).

Texcel V4 (dynamometer controller) and Dewetron's amplifiers are controlled over RS-485 while Bosch BEA gas analyzer 460 over RS-232. As engine response is not known in advance the main role of the ECU is to protect the prototype engine and not allow user to break it down by accident. Every command from automatic control (PIDbased) or given by the user is being filtered by so called Watchdog system. This system verifies if either control given by user can be executed or system has to be put in a safe-state (no ignition/injection allowed, engine slowed down aggressively by the dynamometer). PID controls are implemented on the real time computer. There is an independent loop for every PID-controlled actuator. The PID's can be automatically calibrated using Ziegler-Nichols tuning method (heuristic iterative method) or manually by typing $\mathrm{P}, \mathrm{I}$ and $\mathrm{D}$ values.

\subsection{OD diagnostic model}

A Single Zone Model has been assumed for calculating heat release from the pressure signal. Gas composition, pressure and temperature is assumed uniform, fuel is evaporated and perfectly mixed. For a diagnostic model the gas exchange phase is not calculated, heat release calculation starts at Inlet Valve Closing (IVC) and ends at Exhaust Valve Opening (EVO). Net heat release rate is calculating using standard formula (9) as in Heywood [8]:

$$
\mathrm{dQ}_{\text {chem }} / \mathrm{d} \theta=\mathrm{k} /(\mathrm{k}-1) \mathrm{PdV} / \mathrm{d} \theta+1 /(\mathrm{k}-1) \mathrm{VdP} / \mathrm{d} \theta
$$

The polytropic constant $\mathrm{k}$ is calculated from $\log \mathrm{P}-\log \mathrm{V}$ where compression and expansion curves can be approxi- 
mated by linear function. The model calculates work, power, torque, IMEP, heat release and temperature.

\section{Additional remarks and future challenges}

\subsection{TDC}

It is not possible to use a Top Dead Center (TDC) sensor due to combustion chamber construction. A wrongly set TDC can lead to serious errors (Fig. 10) while calculating volume-based quantities $(\mathrm{dV} / \mathrm{d} \theta)$. In PAMAR-4 engine the volume function resulting from piston motion (3), (4) has inherent $\phi$ phase, which can be changed during engine operation resulting in Variable Valve Timing. By using 2 encoders, one correlated with intake piston motion and second one with exhaust piston motion the difference between their indications allows measuring current $\phi$. The base offset and TDC position is measured with dial gauges with hand-rotating the shaft. Dewesoft also allows TDC detection while motoring the shaft (without combustion). Pegging (referencing the output to absolute pressure) is currently done by measuring the reference pressure using additional absolute pressure sensor, but there are many more possibilities [14].

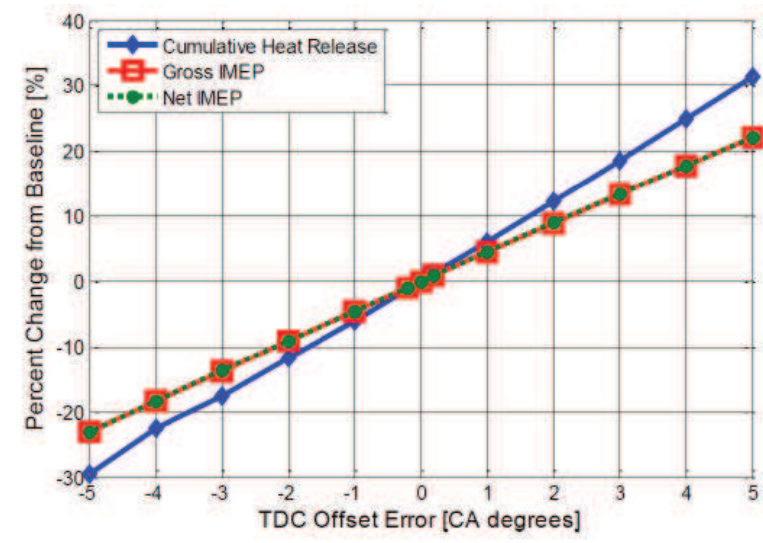

Fig. 10. Effect of TDC offset on cumulative heat release and IMEP [13]

\subsection{Scavenging and trapped mass}

Currently there is no equipment available on the test stand to measure precisely trapping and scavenging efficiency. This makes trapped mass and concentration uncertain and, as it is a 2-stroke, using an oxygen sensor is questionable (air used for scavenging would disturb it's indication) and then AFR ratio is not known precisely.

\section{Preliminary test bed results}

The PAMAR-4 has been preliminarily tested on gasoline with direct injection into the combustion chamber with spark ignition. For initial tests the rotational speed has been limited to 800 RPM and Eaton was used only to start an with $20 \%$ power, then bypassed. Start of ignition was about $5 \mathrm{deg}$ aTDC and lasted for $40 \mathrm{deg}$. Maximum pressure was 68 bar with IMEPn 19.2 bar and torque 160 Nm@770 rpm, work per cycle was $997 \mathrm{~J}$ thus engine power was 28 kW@770 rpm.

Maximum pressure was observed at $20 \mathrm{deg}$ aTDC, while maximum pressure rise rate was about $5.4 \mathrm{bar} / \mathrm{deg}$. The Fig 11 presents in-cylinder pressure and heat release.
As it can be seen there is a need to improve signal filtering and signal processing resolution as heat release is oscillating. Because the pressure signal wat not smoothed the heat release, which has a component proportional to the pressure derivative (9) and thus is very sensitive to the signal quality, was giving false results in range (-80:-20) and (70-90) CAD. The $\mathrm{p}-\mathrm{V}$ graph (Fig. 12) can be used for calculating mean polytrophic exponent for compression and expansion.

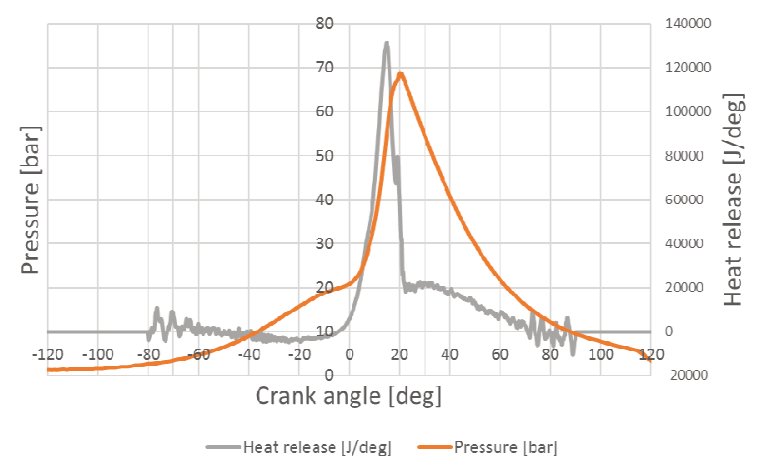

Fig. 11. Preliminary results from PAMAR-4 engine - pressure $[\mathrm{Pa}]$ vs crank angle [deg]

The conformance of numerical model with test bed results is not satisfactory yet (Fig. 13). Big discrepancies can be seen for compression and expansion. In author's opinion it can be caused by wrong heat transfer calculations. The Woschni's formula has been taken as is and cylinder liner temperature has been assumed constant. In PAMAR-4 engine total stroke to bore ratio is more than 7 (for 2 pistons), the exhaust-side liner is cooled while the intake one not. Additionally, the initial gas composition is not known exactly at the moment for a OD model, which leads to errors in results depending on specific gas constant or $\mathrm{c}_{\mathrm{p}}$.

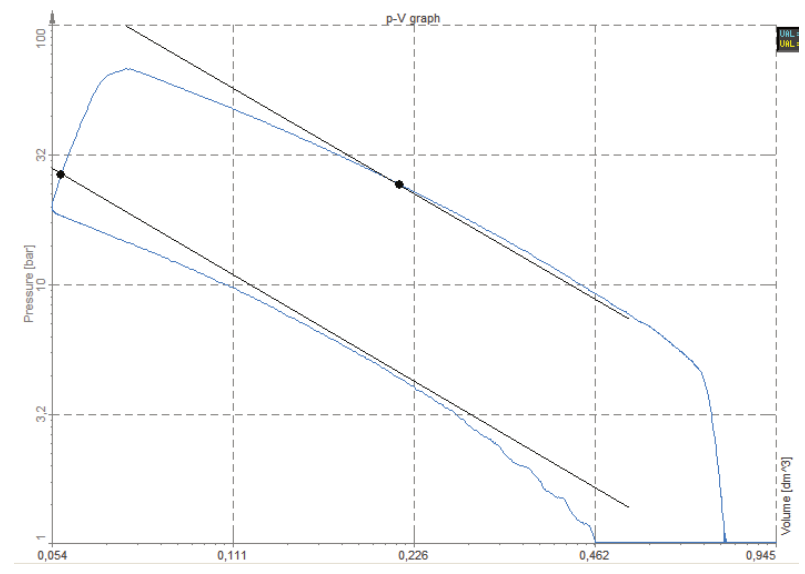

Fig. 12. Preliminary results from PAMAR-4 engine - pressure [Pa] vs volume $\left[\mathrm{dm}^{3}\right]$

\section{Summary and future work}

A PAMAR-4, 2-stroke, opposed-piston barrel engine, has been designed, build and mounted on the specially designed test bed. As there were no ready-made tools which can be used for analyzing the 2-stroke opposed-piston engine operation authors developed two Single Zone Models (predictive and diagnostic). The equipment and software of the test bed were presented. 
Further work will mainly cover the development of a predictive model, which will be upgraded, calibrated and validated with test bed results for various loads and fuels and finally re-written from Matlab to LabView. It will be used for implementing a closed-loop predictive control system basing on cylinder pressure signal. Second model (diagnostic) will be expanded by taking into account fuel injection and blow-by loses. Engine injection and ignition map will be optimized for efficiency.

A test bed should be extended with additional sensors and equipment to allow gas marking to accurately determine scavenging efficiency, trapping efficiency and purity vs delivery ratio for given rotational speed and load. It will allow determining the in-cylinder gas composition.

The measured torque and IMEPn testify to the possibility of obtaining a high power-to-volume ratio in the future while working under the full load. After optimizing the injection and ignition map there will be a possibility to find out what is the achievable efficiency.

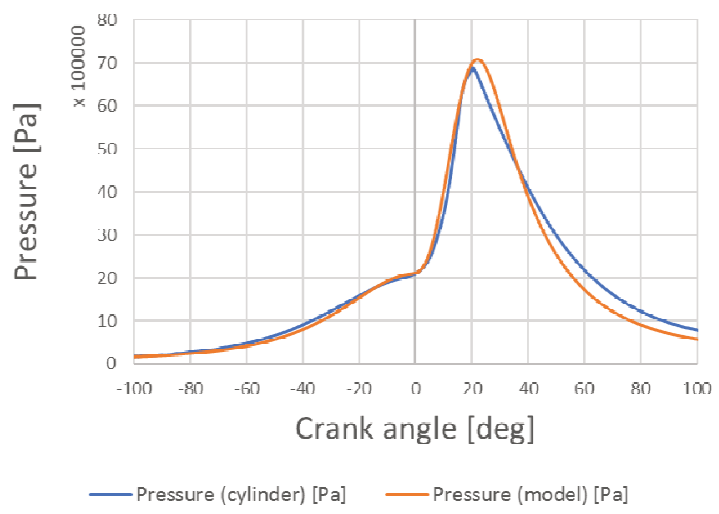

Fig. 13 Preliminary results from PAMAR-4 engine vs 0D model

\section{Nomenclature}

$\begin{array}{ll}\text { OP } & \text { opposed-piston } \\ \text { DI } & \text { direct injection } \\ \text { SI } & \text { spark ignition }\end{array}$

\section{Bibliography}

[1] PIRAULT, J.P., FLINT, M. Opposed piston engines: evolution, use, and future applications. Warrendale: SAE International. 2009.

[2] HEROLD, R.E., WAHL, M.H., REGNER, G. et al. Thermodynamic benefits of opposed-piston two-stroke engines. SAE Technical Paper. 2011, 2011-01-2216.

[3] SHARMA, A., REDON, F. Multi-cylinder opposed-piston engine results on transient test cycle. SAE Technical Paper. 2016, 2016-01-1019.

[4] Pinnacle Engines, Inc. [Internet]. 2016. Available from: www.pinnacle-engines.com.

[5] KANELLOS, M. New vehicle engines almost here: this time for real [Internet]. Available from: www.forbes.com/sites/ michaelkanellos/2015/07/15/new-vehicle-engines-almosthere-this-time-for-real.

[6] MAZURO, P., Rychter, T., Teodorczyk, A. Piston engines with cylinder axis parallel to drive shaft axix - classification and review. Journal of KONES Powertrain and Transport. 2007, 13(3).

[7] GUPTA, R.N., YOS, J.M., THOMPSON, R.A. A review of reaction rates and thermodynamic and transport properties for the 11-species air model for chemical and thermal nonequilibrium calculations to $30000 \mathrm{~K}$. Nasa Technical

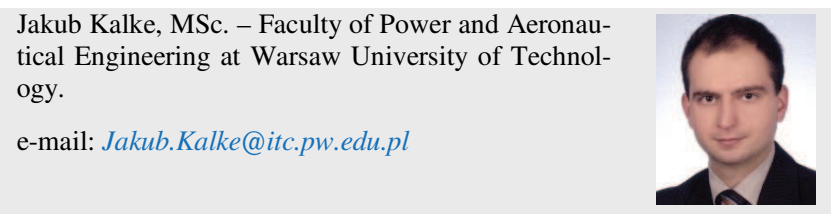

Paweł Mazuro, DSc. - Faculty of Power and Aeronautical Engineering at Warsaw University of Technology.

e-mail: Pawel.Mazuro@itc.pw.edu.pl
TDC top dead center

FPGA field-programmable gate array

ECU engine control unit
Memorandum 1989; Available from: ntrs.nasa.gov/ search.jsp?R=19890011822.

[8] HEYWOOD, J.B. Internal combustion engine fundamentals. New York, McGraw-Hill. 1988.

[9] WOSCHNI, G. A universally acceptable equation for the instantaneous heat transfer coefficient in the internal combustion engine. SAE Technical Paper. 1967, 670931.

[10] SIHLING, K., WOSCHNI, G. Experimental investigation of the instantaneous heat transfer in the cylinder of a high speed diesel engine. SAE Technical Paper. 1979, 790833.

[11] GHOJEL, J. Review of the development and applications of the Wiebe function: A tribute to the contribution of Ivan Wiebe to engine research Review of the development and applications of the Wiebe function : a tribute to the contribution of Ivan Wiebe to engine research. International Journal of Engine Research. 2010, 11(4).

[12] REGNER, G., JOHNSON, D., KOSZEWNIK, J. et al. Modernizing the opposed piston, two stroke engine for clean, efficient transportation. SAE Technical Paper. 2013, 2013-26-0114.

[13] KAUL, B., LAWLER, B., FINNEY, C. et al. Effects of data quality reduction on feedback metrics for advanced combustion control. SAE Technical Paper. 2014, 2014-01-2707.

[14] RANDOLPH, A. Methods of processing cylinder-pressure transducer signals to maximize data accuracy. SAE Technical Paper. 1990, 900170.

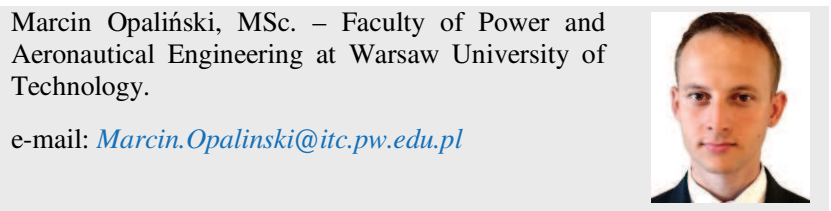

